\title{
School guidance counsellors learning through work experience placements
}

Gerry Jeffers

Education Department,

National University of Ireland, Maynooth,

Co.Kildare

Tel 353-1-7086087_Fax 7084610Ｅ-mail gerard.jeffers@may.ie 


\title{
Reflecting on work experience placements as teacher preparation
}

\begin{abstract}
Work experience placements feature increasingly in mainstream schooling. They are seen as presenting young people with engaging and relevant learning opportunities. As with other changes in our understanding of schooling, this shift carries implications for the on-going education of teachers. One way of preparing teachers with some of the knowledge, skills and attitudes required to implement work experience programmes in school is to give them the opportunity to taste 'work experience' for themselves and then to reflect on their own learning. This article reports on the reactions of trainee school guidance counsellors to placements in a variety of settings as a compulsory part of a oneyear, full-time training course. The data suggest a pattern of course participants moving from initial resistance towards greater empathy for young people in workplace situations.
\end{abstract}

\section{Context}

Work experience placements feature increasingly in mainstream schooling. They are seen as presenting young people with engaging and relevant learning opportunities. When senior cycle education in Ireland was restructured in the mid-nineties, new programmes made 'orientation to adult and working life' a more explicit goal than had previously been the case. Now, three of the four programmes on offer to 15-18 year olds include work experience as a pivotal component with placements typically lasting one or two weeks on one or more occasions during the school year. Feedback from students to the Transition Year Programme (TYP), the Leaving Certificate Applied (LCA) and the Leaving Certificate Vocational Programme (LCVP) attest to the popularity of these placements. Evaluations of these three programmes also underline the centrality of work experience placements to the relative success of these curricular innovations (Department of Education 1996, Millar and Kelly 1999, Granville 1999, Department of Education and Science 2000, Smyth et al, 2004).

Perhaps surprisingly, this development over the past decade has been achieved mainly with the informal rather than formal co-operation of employers and employer 
organisations. Generally, individual employers - from large corporations to selfemployed tradespeople - respond most co-operatively when approached by young people or their teachers in search of a placement, as if they know instinctively how much educational, social and economic sense work experience makes.

Schools report that while employers are frequently willing to offer young people placements, they don't always follow through with meaningful tasks ${ }^{1}$. The caricature of work experience as a week or fortnight spent making coffee (for others) and photocopying, has some basis in reality. Some companies, of course, ensure that students on placement undergo some orientation to the specific workplace, have definite tasks to perform, and a specific supervisor to relate to during the placement. Other employers appear less organized, and while well intentioned, seem unsure about what to do with the student on placement.

Meanwhile schools have been learning 'on the job' how to maximise the learning from work experience placements. The Department of Education and Science support services for the three programmes, in association with the National Centre for Guidance in Education, produced a set of guidelines for schools offering the TYP, LCA and LCVP. (Department of Education and Science, 1998). This material is a valuable resource for educational professionals with responsibility for work experience programmes. Firstly, the guidelines emphasise the importance of preparing student and employer for the placement by focusing on purpose, expectations about outcomes, and the responsibilities of the various parties throughout the placement. The guidelines highlight the importance of student de-briefing after the placement. Reflections that combine oral, written, individual and group presentations are suggested. Creating time and space immediately after a placement so that young people can 'tell their stories' to their teacher and their peers and thus learn through reflection is seen as vitally important.

For the professionals working in schools, the tasks involved in preparation of young people for placements, the liaison with employers who facilitate work experience, and the 
de-briefing of students following placements represent relatively new areas of professional practice. Patterns of responsibility for work experience programmes within schools vary; sometimes a teacher's subject background may have no apparent connection with a student's upcoming work placement, though the teacher may become involved. Frequently some or all of the responsibilities involve the guidance counsellor. In Ireland, the Education Act (1998) requires schools to provide students with 'appropriate guidance to assist them in their educational and career choices' (section 9c). This reflects, to some extent, a tradition that has developed since the late 1960s where schools employed dedicated professional guidance counsellors, frequently people with previous experience as subject teachers, who took particular responsibility for personal, educational and vocational guidance. The most common route for teachers to become formally recognized as school guidance counsellors is to undertake a dedicated course in guidance and counseling. Typically this involves a one-year full time course, combining school placement with classes, lectures and workshops in a university.

\section{An initiative within the education of Guidance Counsellors}

The growing importance of work experience in schools has implications for the guidance and counselling function. In some cases guidance counsellors' involvement with the new programmes, particularly work placements, has been extensive and resulted in a shift in priorities and even in role identity ${ }^{2}$. Elsewhere, perhaps due to the pressure of other work - including counseling related to personal, educational and career issues, consultation with parents and referral agencies, psychological assessments - counsellors have been less engaged in the process. Consequently, other teacher colleagues, rather than guidance counsellors, have emerged as work experience co-ordinators.

School guidance counsellors' contributions to the development of TYP, LCVP and LCA - the programmes with work experience placements as intrinsic components - can be grouped into three broad categories:

\footnotetext{
${ }^{1}$ For a fuller exploration of some of the issues facing employers offering placements see 'Work Experience can be the University of Life' by Gerry Jeffers in Business and Finance, magazine, $6^{\text {th }}$ November, 2003.

${ }^{2}$ It is also worth noting that in some schools teachers other than guidance counsellors have taken responsibility for work experience so that a complex pattern of provision is emerging.
} 
1. As advocates for, or against, the programmes. This function - with students, parents and teaching colleagues - takes place formally and, very significantly, informally. It can be that within school cultures withering comments about programmes can often have much more impact than a power-point presentation and so need to be challenged. Guidance counsellors' opinions on school programmes are clearly noted by their colleagues, students and parents.

2. As designers and planners of particular programmes and modules. The usual structures for the organisation of programmes such as TYP, LCVP and LCA in schools involves small core teams of three or four staff. The guidance counsellor is often a member of such teams, and in schools that offer all three programmes, of all three teams. The guidance counsellor may often be a particular voice for greater emphasis on personal and social development as well as for stronger links between school and local communities.

3. As co-ordinators, teachers and facilitators of specific features within the programmes. Preparing students for work experience placements, monitoring their progress while on placement and de-briefing students after the placement are very particular examples of such activity ${ }^{3}$.

Because of this emerging emphasis on the value of work experience placements for students in second-level schooling, the one year full-time Higher Diploma in School Guidance and Counselling (HDSGC) offered by the Education Department at the National University of Ireland, Maynooth includes a compulsory element of 'work experience' for trainee school guidance counsellors. The informing rationale is that course participants encounter a similar learning experience to what their future students will meet during work experience placements, albeit taking account of variations in age, life experience and social competence. The work experience component of the HDSGC takes place in early January and the rest of this article seeks to describe and analyse the experience of this innovation, for which the author has responsibility, over the past three years.

\footnotetext{
${ }^{3}$ Some of the challenges for Guidance Counsellors arising from these curricular changes are explored in 'The Guidance Counselor and the Senior Cycle' in Guideline, newsletter of the Institute of Guidance counselors, October 2003.
} 


\section{Structure of placements}

The aspiring school guidance counsellors are briefed in mid-November and encouraged to seek work experience placements that they will find 'challenging'. The emphasis is on encouraging individuals to look outside their traditional frames of reference. They are encouraged to look at jobs or workplaces that they have never even considered previously. So, for example, someone who grew up in a family of professionals might search out a work experience placement on a factory floor; a person with a strong rural background might go to a city bank; someone whose experience had been predominantly in academic environments might find a placement involving manual dexterity. The aspiring guidance counsellors are expected to approach employers directly and negotiate their own arrangements. The placement takes place in the first two weeks of January each year. De-briefing takes place on immediate return to university classes. This takes the form of individual oral presentations to the class group followed by group discussion. Students also have the option of submitting a written account of their reflections on the experience and receiving written feedback on such assignments. The suggested focus of reporting is on

- what I did

- what I learned about the workplace

- what I learned about myself

- implications of the placement for work experience in school, in particular what may be of benefit to school students when they go on placement.

The remainder of this paper focuses on some themes emerging from this reflective process among course participants over three years.

\section{Debriefing}

A formal group debriefing session takes place over four hours on the first day back in the university immediately after the placement. The purpose is four-fold:

- to present participants with opportunities to relate their own individual stories about their placements to an interested audience, 
- the allow the full class of twenty-four participants insights into different work environments, into the practical opportunities and problems that arise during the course of a placement, and

- to experience the power of the process of learning through reflection on a placement; this is relevant to their own learning but also with a view to convincing participants of the value of a reflective de-briefing for their own teenage students after a workexperience placement.

- to shed new light on- and challenge - viewpoints, especially related to workplaces, that are often partial, strongly-held and highly individualistic.

The facilitator has a key role to play in enabling such learning to take place, initially by developing an atmosphere of trust so that an arena is constructed where basic questions about workplaces can be explored, where fixed ideas can be re-examined and where previous perspectives can be readjusted without loss of face. As Kolb (1984) remarks:

............one's job as an educator is not only to implant new ideas but also to dispose of or modify old ones. In many cases, resistance to new ideas stems from their conflict with old beliefs that are inconsistent with them. If the education process begins by bringing out the learner's beliefs and theories, examining and testing them, and then integrating the new, more refined ideas into the person's belief systems, the learning process will be facilitated.

The importance of talking together immediately after the placement is based on a belief that such de-briefing offers significant learning opportunities for future guidance counsellors to explore and interrogate their own attitudes to aspects of working life, job satisfaction, career paths, and development, and the crucially important area of workplace relationships.

Writing about the reflective practitioner, Schön (1991) contends that one of the ways in which reflecting-in-practice differs from technical rationality relates to the element of surprise. When teachers venture out from their familiar workplaces, i.e. schools, into new workplace environments the possibilities for surprise abound. The experiences here 
suggest that new discoveries about workplace environments are also accompanied by participants’ insights into their own expectations, attitudes, values and worldviews.

\section{Securing placements}

At the debriefing, participants typically began by recounting how they secured the placement. Some described the mixed emotions they had when the task was assigned initially. Many spoke of experiencing both apprehension and excitement. There were also those who admitted to feelings of reservations about the value of the overall process; their perspective was that as they were already familiar with a variety of workplaces, these placements were pointless and there was nothing to be learned.

Accounts of attempts to secure a placement suggest patterns not dissimilar to what school based co-ordinators find among students who participate in programmes with workexperience components. Some quickly make all the necessary arrangements while others either delay or encounter difficulties in obtaining their preferred placement. In such situations, stress levels often increase and it can be quite powerful to hear otherwise competent adults reveal how anxious they became about arranging a particular placement. In some cases, the invitation to set themselves a challenge is not really taken up and participants have admitted to securing a placement through a relative or friend in a relatively 'safe' environment. However, students in each of the three years reported on work environments that included shops, factories, building sites, offices, wholesalers, hospitals, auctioneering companies, public houses, a farm, a bank, restaurants, a training centre for Travellers, university offices, a physiotherapy practice, a bakery, voluntary organizations, a printing works, veterinary clinics, a DIY centre, florists, an equestrian centre, newspaper offices, a communications company and science laboratories.

Employers' reactions to people seeking work experience placements also reflect a broad range of responses with participants experiencing mainly enthusiasm and delight but with occasional indifference and rejection. Stories about participants being refused a placement are always effective entry points into explorations of their views of themselves and of workplaces and each year there were such examples. A number recounted that conversations with potential employers revealed attitudes to teaching as an occupation 
that were clearly hostile, though this was not always accompanied by to a refusal to offer a placement. For example, when, during the de-briefing, one participant remarked that the owner-manager of a beauty salon was quite surprised that a qualified teacher wanted to do a work placement in a salon there was a flood of comments unleashed from the course participants indicating sizeable gaps between teachers' own collective professional self-image, and what they see as the views of many employers.

\section{Insights}

The reporting on the activities undertaken was generally brief and straightforward. A striking feature of the process with these adults was how little time was devoted to describing the detail of what they actually did; they were keen to move towards a reflective and critical anaylsis. This contrasts with this author's experience of many years facilitating de-briefing sessions with teenagers, in that the latter, in both oral and written presentations, were often strong on description and weak on analysis.

The course participants touched on a wide range of incidents and issues. They were keen to connect their experiences with the realities of preparing young people for such placements. At the risk of over-rigid categorisation, these trainee guidance counsellors many of whom were also experienced teachers -who undertook work placements as part of the programme tended to highlight their learning in four particular areas.

\section{Self-awareness}

1. While a work placement offers practical experience of doing specific job and career related tasks, much of the learning during a brief placement concerns insights into oneself, one's preferences, inclinations, strengths and apprehensions. This leads to a focus on the possibilities of work experience placements for increasing self-awareness. For example:

I would not be suited to the work of a packer or grader. I would get no job satisfaction out of it at all and probably would get depressed having to stand at a machine every day.

Some came to recognize that, as teachers, they have grown to expect variety and even unpredictability in their working day. One said 
I disliked being confined to one space and I found the repetitiveness of the daily routines extremely lacking in challenge.

While another remarked

I don't think I could do that (work in hotel) for very long.

Individual experiences raised important questions for the particular people who were involved. The participant on placement in a workplace threatened with redundancy regarded it as a very special experience. Another felt that the revelation that she needs constant variety and stimulation at work was an important one. A further student, impressed by the level of care evident on a hospital placement, posed the challenging questions: would the same levels of pastoral concern be evident on school corridors as he had observed on busy hospital corridors?

\section{The value of preparing young people prior to a placement}

2. Secondly, there was a strong realization among the group that, because workplaces are social environments where social skills, particularly communication skills, are vitally important, the preparation of young people for a work experience placement is important. Many agree that, having experienced and reflected on their own placement, they had a heightened awareness of how useful it could be to work on developing the confidence and competence to deal with a wide range of people and situations prior to going on a work experience placement. Role-play was frequently suggested as an appropriate methodology.

Many participants remarked on how central communication skills were to the tasks they had to perform and the situations in which they found themselves. For example,

I came to realize that interacting with a wide cross-section of people, especially customers, is at the heart of this and many other jobs. If you are not comfortable at this, then what chance (is there) of job satisfaction?

What looks simple, like doing well on the telephone, would probably be a huge challenge for many of my students. 
This emphasis on social skills also led to some reappraisal of the kinds of work environments that are suitable for placements.

It (placement in a hairdressing salon) is an excellent means of helping students develop their social skills, and of realizing the demands of working life.

While you can get a lot of insights into people from working in an offlicence, I don't think it's an appropriate place for a young person on placement.

Frequently during the de-briefing, course participants focused on relationships in the workplace - who bosses whom, who relates to whom, how people get on, how employees deal with the public and so on. There was a collective emphasis on the importance of 'people skills' in so many different workplaces. This led some participants to highlight not only preparation for placements, but to look at the development of such skills within the wider curriculum rather than as merely ‘bolt-on’ activities.

I don't think that a single information session before a placement would be much help. Some students would need a whole programme to prepare them for the 'people' activities they will encounter on a placement.

A dominant strand among the participants' responses was the extent to which they were keen to emphasise how much more seriously they plan to take work experience with their own students.

I have always been a great believer in 'learning by doing'...this experience has made me even more steadfast in that opinion.

My future organisation of work experience has been greatly informed by this placement, as well as being an insightful experience into myself, and this particular area of work.

\section{School as a workplace}

3. As participants reflected on their placements, a contrast between the familiar work environment of the school and the less familiar environments of other workplaces emerged as an important strand. This perspective led to a fresh evaluation of the school as a workplace with its attractions and drawbacks. 
As already noted, much work was perceived as 'repetitive' with routine tasks often described as 'lacking challenge'. In contrast, there were comments about the variety, stimulation and unpredictability of life in school; participants' familiar workplace was regarded in a fresh light. Most course participants were already teachers in secure employment. Exposure to varied workplaces appeared to lead to a greater appreciation of the insecurity that is sometimes associated with particular employments. For example:

The discovery during the placement that the company was about to close, and that 49 jobs were on the line, added strong doses of realism to my placement.

There were also insights into different value systems.

I missed the social dimension that I associate with the staffroom in school. The (placement) workplace was dominated by targets, which were very specific, and money was a very real motivator. There was a very definite hierarchical structure in place, and people were told, in no uncertain terms, what to do.

On the other hand, occasionally the excitement of the new workplace generated great enthusiasm in some.

The variety was great, meeting the people was great... after a week I was considering changing my profession!

In the author's experience of debriefing school students following placements, they too often comment on the differences between school and various workplaces. Indeed, for some young people increased motivation for schoolwork and a more focused career plan can result from a taste of a placement that is seen as dull and monotonous. As the aspiring school guidance counsellors reflected on their own placements, they recognized and welcomed the potential of harnessing insights into a contrast between school and work for motivating students.

There were other partial illuminations. Two complementary anecdotes forcefully underline the concept of 'status' in the workplace. On placement alongside a medical consultant in a hospital, one participant was given a white coat. She reported that some patients consequently presumed she was part of the 
professional medical team. She admitted feeling embarrassed that she might be engaging in some form of fraudulent behaviour. By contrast, a classmate on placement in a DIY store tasted a different form of embarrassment. She found herself cleaning toilets and reported that she felt a strong desire to explain to passers-by, especially those who might have recognized her, that she was a teacher on placement and not an actual cleaner!

\section{The value of a reflective debriefing}

4. The fourth major strand to emerge through the de-briefing was a growing appreciation that learning from a work experience placement is complex and challenging. In addition to recognizing the importance of preparation, participants also came to value the power of a reflective group debriefing. Particularly evident was a noticeable shift towards greater empathy with young people undertaking placements.

Some spoke openly about the self-doubt that many experience when starting in a workplace for the first time. For example,

What caused me a lot of anxiety when starting my placement was wondering whether I would be able to do what I was asked.

Uncertainty sometimes gave way to a realization that they had agreed to a placement without checking out the details of the work that might be involved.

I was thinking: this is not what I signed up for, but, also realised that I did not clarify what my duties (in the camera shop) would be. I never want to work in a shop again.

Even when what has to be done is clear, there can still be apprehension.

All the tasks that were required of me seemed extremely straightforward in theory, but in practice, they were quite difficult to complete.

Many of the 'lessons' that participants choose to highlight from their placements involved basic points, that at one level might look like 'common-sense' but which served to highlight significant differences between classroom realities and ones in others workplace. Comments about simple organisational details abound. For example,

It never even occurred to me to ask what I should wear. 
The point about confidentiality is a most relevant one for all dealings with preparing students for work placements.

I'll look at health and safety issues in a fresh way after this placement.

Simple decisions like how I would spend my lunch-breaks assumed great importance.

These and other comments during feedback were often accompanied by references to age such as ‘if I was this apprehensive as an adult, I don’t think I would have handled it very well as a 15 year-old' or 'I admire teenagers who can go into such situations and respond to such challenges'. Increased empathy with young people about to embark on placements was very evident.

This increased empathy was also furthered by the realization that employers' willingness to offer work experience placements is not always followed up with practical measures. Some course participants came face to face with this reality. For example,

The first issue I was faced with on turning up to work placement on Monday morning was that he (the line manager) had obviously not mentioned me at all to the other employees, including the shop manager. I felt very awkward and uncomfortable and would have been happier had he warned them about me.

Incidents such as this increased participants' awareness of how vulnerable young people can be on work experience placements, and further reinforces points made earlier

Collective debriefing enables participants to locate their learning in context, to evaluate their experiences with those of others. Individual activities to encourage reflection on the process met with different responses. For example, one participant wrote:

While the diary did help me consolidate my learning, as the written report has, perhaps a conversation with someone who understood the purpose of the placement would have helped even more.

Learning-by-doing also draws attention to combining written work with oral presentations: 
Whilst writing this report I now see the value of writing down what is learned from the experience. It enables one to reflect on the learning. If I didn't complete this report I might not see its value for students after they return from placement.

Following the de-briefing, another remarked:

Listening to all those stories was a great privilege; it was great to hear people, whose personalities you know, talking about how they fared in particular situations.

\section{Reservations}

While the process of preparation, placement and de-briefing was shown to be a very effective way of mapping the myriad issues associated with the organization and operation of school-based work experience programmes, some participants expressed reservations. An obvious one relates to maturity.

Of course the main flaw is that I am 40 not 16 and therefore comparisons are very difficult.

As already indicated, others displayed some hostility towards the idea of a placement.

At one point I even felt nauseous and then I felt resentful and irritated at having to go through this experience.

As with school students, questions around 'payment' for work experience also emerged from the participants. As one remarked,

I was unimpressed with the idea of doing unpaid work and I believe that young people (in school) who work part-time share these feelings.

Increasingly, teachers report that this issue surfaces in discussion at the preparatory stages of a work experience programme. One of the effects of the Irish economic boom of the late 1990s was that part-time work became widely available and the number of young people who held part-time jobs during school term increased. One consequence of this is that, at age 15-16, young people discuss their experiences among themselves and discourse about workplaces, about pay and working conditions, and about part-time working all feature more prominently among Irish teenagers than ten years ago. This has implications for the school-based work experience organizer. Distinguishing between 'work experience' as primarily an educational activity, and part-time work as primarily 
an economic engagement, is not always immediately appreciated. The situation is exacerbated as some employers have developed a tradition of concluding the placement with a financial 'gift' to the teenager. Many employers, especially 'not for profit' ones can't 'compete' with this, and some schools report that the possibility of payment at the end of a placement is a factor influencing choice of placements. In general, it is a problematic area and an important one to discuss among those who will become work experience organizers. It's also worth noting that some schools have developed two placement blocks in their Transition Year programmes, and insist that one must have a ‘community service’ dimension.

\section{Moving forward}

If one of the most important insights about work experience programmes is that we cannot presume that learning happens automatically, then there is no guarantee that sending a group of teachers on placement will, in itself, prepare them for the task of co-ordinating work experience programmes in schools. However, the evidence here suggests that they have become, first of all, less apprehensive about undertaking such a responsibility. Secondly, a number of course participants remarked that, having participated in what they describe as 'a positive de-briefing session', they have a much clearer picture of the dynamics of a 'good' reflective debriefing. Thirdly, participants say that having their own individual stories to tell about a work experience placement increased their confidence for organizing work experience programmes for young people. Fourthly, there was the recognition that not all placements are exciting all the time. A number saw at first hand, that what might be described as a 'negative' placement, nonetheless offered lots of learning potential.

Many contended that one of the biggest lessons learned from the experience was an increase in empathy for young people about to embark on a work experience programme. This in itself must be regarded as a very successful outcome of any teacher education programme. Some reported how, during the debriefing session, they realized the importance of sensitive listening and facilitation, and how all 
participants deserve the opportunity to voice their own stories. The point was also made that a sensitive facilitator, aware of the multiplicity of issues associated with work experience, can build on people’s own experiences to increase significantly their understanding of workplaces.

\section{Discussion}

The inclusion of work experience placements is increasingly a feature of schoolbased programmes. Critical questions need to be posed about the nature of the learning that can take place through such placements. Enhancing the professionals who will prepare, monitor and de-brief students with appropriate knowledge, with skills and attitudes, poses a further set of questions. The evidence here suggests that the possibilities and complexities of young people's learning through work experience placements are likely to be more keenly appreciated if and when they participate in a placement programme themselves. The trainee school guidance counsellors' collective reflection of a variety of placements brings into focus, in particular:

- the value of work experience programmes to increase self-awareness;

- the need to see learning through work experience placements as involving three dimensions: (i) adequate preparation; (ii) appropriate monitoring and (iii) reflective debriefing;

- the importance of communications skills in work settings;

- the potential value of work experience to motivate young people;

- the importance of reflective de-briefing.

The feedback from those learning to become guidance counsellors also raises an important question for schools: do some workplaces create more capacity for young people's learning and personal development than others? The evidence presented here highlights how vulnerable adult learners can feel in new and unpredictable situations. Hence, it seems reasonable that schools should be confident that the workplace environment in which students find themselves should be broadly positive towards learning through work experience. 
Environments characterized by hostility or negativity are best avoided. The presence of a designated 'mentor' for young people on placement, with clear responsibilities for induction, support and providing feedback appears desirable, especially in workplaces with large numbers of employees. Thorough, on-going monitoring of placements by schools also appears to deserve serious attention.

\section{Conclusion}

In the context of lifelong learning, it makes sense for teachers to venture out from the familiar comfort zone of a school environment into the unpredictable, and possibly threatening environments, of different workplaces. The challenge often is to find mechanisms to enable this to happen. A course of preparation for the work of a school guidance counsellor offers a particularly appropriate opportunity for such educational excursions. Learning about unfamiliar workplaces as well as identifying with their students' experiences of their short placements can be energizing features of the continuing professional development of educators.

The overwhelming realization among the group during the debriefing was that placements are worthwhile, that preparation and debriefing are essential, that group debriefing can be powerful, that learning about oneself often overrides what is learned about the workplace, and that social skills are critically important in any workplace. The cumulative effect among the group, following placement and reflective debriefing, was also to promote a deepening empathy with young people on placement, a more critical view of work environments and the identification of factors that are conducive to learning for adults and students alike.

There is also evidence that the programme provides for significant personal and professional development, a not insignificant consideration given Barth's (1990, p.49) assertion that

Probably nothing in a school has more impact on students in terms of skills development, self-confidence or classroom behaviour, than the personal and professional growth of their teachers. 


\section{Bibliography}

Barth, R. (1990), Improving schools from within; teachers, parents and principals can make the difference. San Francisco, Jolley-Bass

Department of Education (1993) Transition Year Programme: Guidelines for Schools, Dublin: Department of Education.

Department of Education (1996) Transition Year Programme 1994-95, An Evaluation by the Inspectorate of the Department of Education. Dublin: Department of Education.

Department of Education (1998) Work Experience at Senior Cycle, Guidelines for Schools offering Transition Year Programme, Leaving Certificate Applied , Leaving Certificate Vocational Programme, Dublin: Department of Education and Science.

Department of Education and Science (2000) Report on the National Evaluation of the Leaving Certificate Applied, Inspectorate, Evaluation Support and Research Unit, Dublin: Department of Education and Science.

Government of Ireland (1998) Education Act, Dublin: Stationery Office.

Granville, G. (1999) In Support of Change: An Evaluation of the LCVP In-Career Development Programme, Dublin: LCVP Support Team.

Jeffers, G. (2002) 'Transition Year Programme and Educational Disadvantage' in Irish Educational Studies, 21, 2 Autumn 2002, Dublin: ESAI.

Kolb, D.A. (1984) Experiential Learning Experience as the source of learning and development, 1984 Prentice Hall New Jersey.

Millar, D. and Kelly, D. (1999) From Junior Certificate to Leaving Certificate : A longitudinal study of 1994 Junior Certificate Candidates who took the Leaving Certificate Examination in 1997, Final Report, Produced for the NCCA by Educational Research Centre, Drumcondra.

Prendiville, P (2004) Developing Facilitation Skill, A Handbook for Group Facilitators, (New edition), Dublin: Combat Poverty Agency.

Schön, D.A. (1991) The Reflective Practitioner, How Professionals Think in Action, London: Ashgate. Smyth, E., Byrne, D., Hannon, C. (in press) The Transition Year Programme: An Assessment, Dublin: Economic and Social Research Institute.

Smyth, E, Byrne, D, Hannan, D (2004) The Transition Year Programme, An Assessment Dublin: ESRI and Liffey Press.

Transition Times, a weekly column on Wednesday in The Irish Times

Transition Year Curriculum Support Service (1999) Writing the Transition Year Programme, TYCSS: Blackrock Education Centre, Dun Laoghaire. Co Dublin.

Transition Year Curriculum Support Service (2000), Transition Year Survey on Co-ordination, Report on Findings, Blackrock Education Centre, Dun Laoghaire. Co. Dublin.

Watts, A.G. editor, (1983) Work Experience and Schools, London: Heinemann. 